Original investigation

\title{
Diel variation in movement patterns and habitat use by the Iberian endemic Cabrera vole: Implications for conservation and monitoring
}

\author{
Ana Rita Grácio ${ }^{a}$, António Mira ${ }^{\mathrm{b}}$, Pedro Beja ${ }^{\mathrm{c}, \mathrm{d}}$, Ricardo Pita ${ }^{\mathrm{b}, \mathrm{d}, *}$ \\ a Departamento de Biologia, Universidade de Évora, Núcleo da Mitra, Apartado 94, 7002-554 Évora, Portugal \\ ${ }^{\mathrm{b}}$ Unidade de Biologia da Conservação, CIBIO/InBio-UE, Centro de Investigação em Biodiversidade e Recursos Genéticos, Pólo de Évora, Universidade de \\ Évora, Núcleo da Mitra, Apartado 94, 7002-554 Évora, Portugal \\ ${ }^{c}$ EDP Biodiversity Chair CIBIO/InBio-UP, Centro de Investigação em Biodiversidade e Recursos Genéticos, Universidade do Porto, Campus Agrário de Vairão, \\ 4485-661 Vairão, Portugal \\ ' CEABN/InBIO, Centro de Ecologia Aplicada "Professor Baeta Neves", Instituto Superior de Agronomia, Universidade de Lisboa, Tapada da Ajuda, $1349-017$ \\ Lisboa, Portugal
}

\section{A R T I C L E I N F O}

\section{Article history:}

Received 9 June 2016

Accepted 15 November 2016

Handled by Adriano Martinoli

Available online 16 November 2016

\section{Keywords:}

Circadian cycles

Movement behaviour

Habitat selection

Microtus cabrerae

Radiotelemetry

\begin{abstract}
A B S T R A C T
Understanding variations in animal movement and habitat selection behaviour over fine spatial and temporal scales remains a particularly challenging goal in ecology and conservation. Here we document for the first time the diel variations in movement patterns and habitat use by wild-ranging Cabrera voles in fragmented Mediterranean farmland, based on radiotracking data (2006-2008) of 25 adult individuals occupying stable home-ranges in vegetation mosaics dominated by wet grasses and shrubs. Results indicated that the proportion of time animals spent moving, the distance moved, and the selection strength of main vegetation types were closely linked behavioural traits, which varied considerably across different periods of the 24-h cycle. In general, voles moved more frequently and over larger distances during daytime (between 06 h15-22 h00), which was when wet grasses were also used more intensively. These patterns were generally consistent across seasons, though during the dry season there was some tendency for a decrease in movement activity during the hottest hours of the day (between 10 h15-14 h00), with peaks around crepuscular hours (06h15-10 h00 and 18 h15-22 h00). Overall, our study provides evidence that Cabrera voles may show notable shifts in habitat use and movement patterns on a finer scale than previously considered. This supports the idea that knowledge of the diel variations in species movement-habitat relationships should strongly contribute to improving local habitat management, as well as effective sampling and monitoring programs targeting the species.
\end{abstract}

(C) 2016 Deutsche Gesellschaft für Säugetierkunde. Published by Elsevier GmbH. All rights reserved.

\section{Introduction}

The survival and reproduction of an animal depends on whether it can satisfy its basic needs, such as food, water, shelter, and breeding sites (Manly et al., 2002). Usually, no single habitat can fulfil all these needs, and thus animals often need to move among habitat types, with habitat selection reflecting a trade-off between energy intake (growth) and mortality risk (Moe et al., 2007; Railsback and Harvey, 2002). This trade-off is determined by animals' responses to a variety of conflicting demands related to physiological needs, food acquisition, forage phenology, photoperiod, predation risk, thermal

\footnotetext{
* Corresponding author at: Unidade de Biologia da Conservação, CIBIO/InBioUE, Centro de Investigação em Biodiversidade e Recursos Genéticos, Pólo de Évora, Universidade de Évora, Núcleo da Mitra, Apartado 94, 7002-554 Évora, Portugal.

E-mail address: ricardo.pita@gmail.com (R. Pita).
}

comfort, social associations, and disturbances (Lima and Dill, 1990; Verdolin, 2006). In the management of a species, it is thus essential to know which habitats are used and why and when animals select some habitats over others (Manly et al., 2002). Identifying the patterns of animal movement and the suite of conditions that defines species habitat requirements is therefore a primary goal in ecology and conservation (Mayor et al., 2009).

To understand the habitat requirements of an animal species it is generally important to have information on how individuals move and shift among habitat types at fine spatio-temporal scales, i.e. along their routine activities within their home-ranges (Ager et al., 2003; Godvik et al., 2009), which in turn implies examining the foraging dynamics at the patch level, while integrating diel cycles in movement behaviour (Moe et al., 2007; Morris, 2014; Onorato et al., 2011; Di Stefano et al., 2009). Most studies regarding species habitat selection, however, are based on a collection of point locations where animals were observed over relatively long 